\title{
Реализация метода
}

\section{направленного гидроразрыва (НГР) \\ при решении геотехнологических задач} управления повышенным горным давлением*

DOI: http://dx.doi.org/10.18796/0041-5790-2021-11-6-12

\section{клишин в.и.}

Доктор техн. наук, профессор,

чл.-Кор. РАН,

директор Института угля

ФИЦ УУХ СО РАН,

650065, г. Кемерово, Россия,

e-mail:klishinvi@icc.kemsc.ru

\section{ОПРУК Г.Ю.}

Канд. техн. наук,

заведующий лабораторией эффрективных технологий

разработки угольных месторождений

Института угля ФИЦ УУХ СО РАН,

650065, г. Кемерово, Россия,

e-mail:opruk@yandex.ru

ТЕЛЕГУЗ А.С.

Младший научный сотрудник

Института угля ФИЦ УУХ СО РАН,

650065, г. Кемерово, Россия,

e-mail: alexanderteleguz@rambler.ru

\section{НИКОЛАЕВ А.В.}

Заместитель главного инженера по технологии

ООО «Шахта «Есаульская»,

650065, 2. Новокузнечк, Россия,

e-mail: Aleksey.Nikolaev4@evraz.com

\section{МАХРАКОВ С.И.}

Генеральный директор

ООО «Шахта «Листвяжная»,

652614, пгт. Грамотеино, Кемеровская обл., Россия,

e-mail:office2@list.hcsds.ru

\section{ПЕЧЕНЕВ И.А.}

Директор

ООО «КарьероУправление № 42»,

653047, 2. Прокопьевск, Россия,

e-mail:ooo@ku42.ru

" Исследование выполненоза счет гранта Российского научного фонда (проект № 17-17-01143).
Представлены метод направленного гидроразрыва (НГР) для управления труднообрушающейся кровлей в угольных шахтах и средства его реализации. Анализируется опыт реализации метода на угольных шахтах Кузбасса для различных технологических задач: поддержание повторно используемых подготовительных выработок; снижение первичного и последующих шагов обрушения кровли, пучения почвы впереди очистного забоя, газовыделения в очистную выработку. Рассмотрены результаты мониторинга и шахтных экспериментов по управлению кровлей с использованием метода сейсмического просвечивания выемочного столба на проходящих волнах.

Ключевые слова:управление горным давлением, поддержание выработок, направленный гидроразрыв, труднообрушаемая кровля.

Для цитирования: Реализация метода направленного гидроразрыва (НГР) при решении геотехнологических задач управления повышенным горным давлением / В.И. Клишин, Г.Ю. Опрук, А.С. Телегуз и др. // Уголь. 2021. № 11. C. 6-12. DOI: 10.18796/0041-5790-2021-11-6-12.

\section{ВВЕДЕНИЕ}

Разработка угольных пластов с труднообрушаемыми кровлями связана с рядом серьезных осложнений. При ведении очистных работ в условиях прочных кровель, склонных к зависанию на значительной площади, при их последующем неуправляемом обрушении в зоне очистного забоя и на сопряжениях его с горными выработками происходят динамические процессы, такие как горные удары и внезапные выбросы угля и газа, провоцируется внезапный выброс угля и газа. Это приводит к снижению производительности труда и безопасности при подземной добыче [1, 2, 3, 4].

На шахте «Баренцбург» архипелага Шпицберген при обрушении труднообрушающейся кровли угольный комбайн подбросило вверх со смещением в сторону крепи [5].

Известно, что Китай является крупнейшей страной по добыче угля, при этом на его долю приходится треть динамических явлений, вызванных обрушением кровли и вы- 
бросами угля, от общего числа в мире $[6,7,8,9,10]$. За последние несколько десятилетий динамические обрушения прочной кровли произошли более чем в 100 угольных шахтах, что привело к многочисленным травмам, несчастным случаям со смертельным исходом, к разрушению выработок и оборудования.

В Австралии компания «Narrabri Coal Operations», расположенная в штате Новый Южный Уэльс, отрабатывала угольный пласт Хоскиссон, где непосредственно над угольным пластом залегал прочный конгломерат мощностью от 15 до 20 м. Его зависание до первичного обрушения при выходе из монтажной камеры достигало до 60 м [11, $12,13,14,15,16,17]$, поэтому во многих странах такая кровля считается признаком динамических явлений $[6,7]$.

Этим диктуется необходимость разработки новых эффективных способов управления такими кровлями в очистных и подготовительных выработках в связи с тем, что существующие методы [18] малоэффективны, а взрывные работы в угольных шахтах опасны.

\section{МЕТОД НАПРАВЛЕННОГО ГИДРОРАЗРЫВА}

В ходе ведения очистных работ в верхней части выработанного пространства и в массиве горных пород над выработанным пространством скапливается большое количество метана, поскольку метан легче воздуха. В момент обрушения кровли происходит резкий выброс скопившегося в завале газа в угольные выработки, в них резко увеличивается содержание метана. Выброс сопровождается мощной ударной волной и может вызвать разрушение и замыкание электрической системы, воспламенение и взрыв газа и угольной пыли. При обрушении кровли происходит поднятие пыли, возможны ее возгорание и заданных выброс в горные выработки.

Для предотвращения динамических явлений в шахтах продолжаются совершенствование и широкомасштабное внедрение уникальной безвзрывной технологии направленного гидроразрыва пород (НГР) $[2,3,19,20]$. Идея реализации метода заключается в том, что на стенках восстающих скважин 1, ориентированных нормально слоистости или под углом, с помощью специального инструмента нарезают инициирующую щель 2 (узел А) заданной формы и размеров, являющуюся концентратором напряжений (рис 1).

Затем щель герметизируют упругорасширяющимся рукавом-пакером 3 и в нее нагнетают насосом 7 по трубопроводам 4, через коллектор 5 в режиме гидроразрыва жидкость. В результате хрупкого разрыва происходит рост щели в заданном направлении. Для осадочных пород прочность на разрыв в направлении по слоистости наимень-
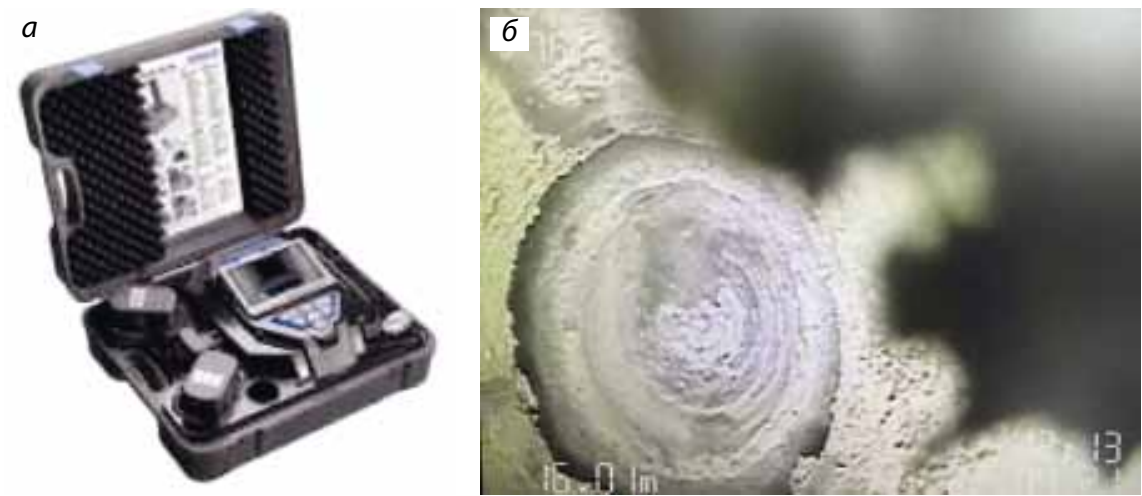

Puc. 2. Видеоэндоскоп (а) и забой скважины с инициирующей щелью (б) шая. Поэтому условие для распространения щели по слоистости является наиболее благоприятным. Расслоение монолитной кровли может быть осуществлено на одном, двух и более уровнях (в зависимости от количества инициирующих щелей, создаваемых в скважине).

Для реализации метода НГР разработан ряд механизированных устройств - щелеобразователей для создания инициирующих щелей в шпуре диаметром 46 мм [2, 3, 20]. Герметизация зоны инициирующей щели осуществляется гидравлическим герметизатором типа «Таурус». Досылка герметизатора к забою скважины производилась при помощи специального комплекта высоконапорных труб. Нагнетание жидкости в зону инициирующей щели зачастую производилось от высоконапорной станции механизированного комплекса.

Контроль эффективности бурения скважины на расчетную глубину и нарезание в забое каждой скважины осуществляются видеоэндоскопом (рис. 2).

После реализации данного метода на шахте «Покуй» (Польша) при первой посадке кровли [20], он широко внедряется польскими специалистами в качестве метода борьбы с горными ударами [21, 22]. Ссылаясь на эти исследования, китайские специалисты считают его идеаль- 
ным методом управления труднообрушающейся кровлей В дальнейшем они использовали метод НГР на двух длинных лавах № LW6305 и № LW5307, что позволило им обеспечить безопасность работы очистных забоев $[8,9,10]$.

В Австралии для реализации метода расслоения кровли на первичную посадку в предварительно подготовленном очистном забое горизонтальными трещинами на разных глубинах применили очень дорогой метод путем создания трещин из скважин большого диаметра, пробуренных с поверхности. В скважинах диаметром 300 мм конец пакера не доводили до забоя скважины приблизительно на 320 мм. При этом расчетным путем определили место заложения предполагаемых трещин разрыва по слоистости со сдвигом каждой новой трещины на 2,5 м или менее, до радиуса 30 м или более [11, 12, 13, 14, 15, 16, 17]. После отхода очистного забоя на 24 м от монтажной камеры произошло обрушение кровли (почти в три раза меньшее по сравнению с предполагаемым - 60 м). В дальнейшем, чтобы избежать образования продольных (вдоль скважины) трещин, предложено создавать инициирующие трещины за счет абразивной струйной обработки стенок скважины. Затем эти прорези были изолированы с помощью горизонтальных пакеров для получения направленного гидравлического разрыва.

На шахтах Кузбасса продолжают применять метод НГР в различных технологических схемах с последующим анализом полученных результатов для продолжения его совершенствования. Широкая область применения метода обусловлена возможностью его оперативного применения и, в большинстве случаев, отсутствием необходимости остановки очистных работ. На шахте «Есаульская» отрабатывалась в особо сложных условиях лава № 26-25бис, расположенная в целике между ранее отработанными выемочными столбами 26-23 и 26-25. Размеры охранных целиков вентиляционного и конвейерного штреков не превышали 6 м, что было вызвано необходимостью максимального извлечения угля.

Основная кровля представлена мелкозернистыми и крупнозернистыми алевролитами с маломощными прослоями песчаников. Смена типов основной кровли контролируется изменением сочетаний литологических типов. Во второй половине лавы преобладали крупнозернистые алевролиты, что характеризует основную кровлю как труднообрушаемую, с возможностью значительного зависания кровли при работе лавы, и как следствие, воз- никновения повышенных нагрузок на крепь усиления сохраняемой части вентиляционного штрека. Согласно проектной документации, проветривание горных работ при отработке запасов в лаве № 26-25 бис осуществлялось по комбинированной схеме с изолированным отводом метановоздушной смеси из выработанного пространства по сохраненной части вентиляционного штрека и выработкам газодренажной сети. При ширине охранного целика 6 м важнейшей задачей при отработке запасов лавы являлось сохранение части вентиляционного штрека № 26-25 бис для изолированного отвода метановоздушной смеси из выработанного пространства вслед за подвиганием очистного забоя.

Совместно с технической службой шахты, сотрудниками Института угля ФИЦ УУХ СО РАН была предложена технологическая схема направленного гидроразрыва кровли для снижения интенсивности проявлений горного давления в сохраняемой части вентиляционного штрека, которая позволила обеспечить «обрезание» консоли кровли над вентиляционным штреком позади очистного забоя и сохранность вентиляционного штрека в период отработки выемочного столба лавы. В первую очередь гидроразрыв производился в вертикальных скважинах с развитием искусственных трещин параллельно напластованию, затем в наклонных с развитием трещины под углом к напластованию с выходом искусственной трещины на контакт между непосредственной и основной кровлями, а также дальнейшим ее распространением по контакту (рис. 3).

Примененная схема гидроразрыва пород кровли в составе разработанного комплекса мер для отработки лавы в особо сложных горно-геологических условиях позволила уменьшить давление на крепь усиления сохраняемой части вентиляционного штрека, что обеспечивало необходимый отвод объема метановоздушной смеси на протяжении отработки всего выемочного столба (рис. 4).

Зависание пород основной кровли в выработанном пространстве способствует увеличению горного давления на краевую часть пласта и на целики угля в зоне опорного давления, которые в свою очередь передают давление на породы непосредственной почвы пласта, это приводит к ее пучению в подготовительных выработках, очистном забое [2]. С целью предотвращения пучения почвы и разгрузки угольного пласта широко применяется способ бурения разгрузочных скважин в пласте угля, снижающих напряжения в краевой части пласта и целиках.
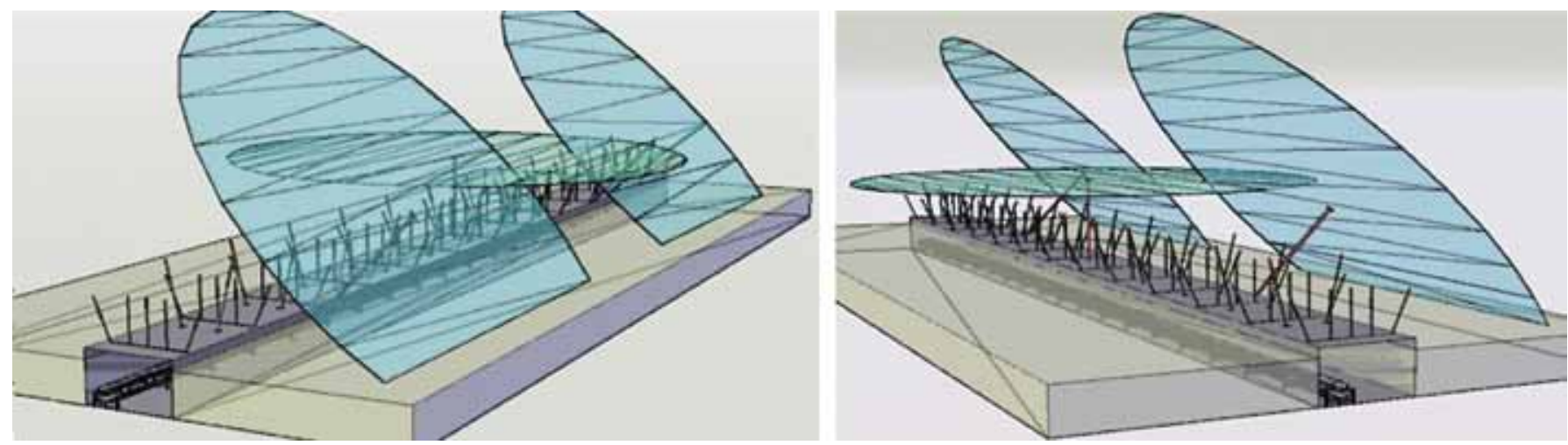

Рис. 3. Пространственная модель образования плоскостей гидроразрыва пород кровли для управления горным давлением 

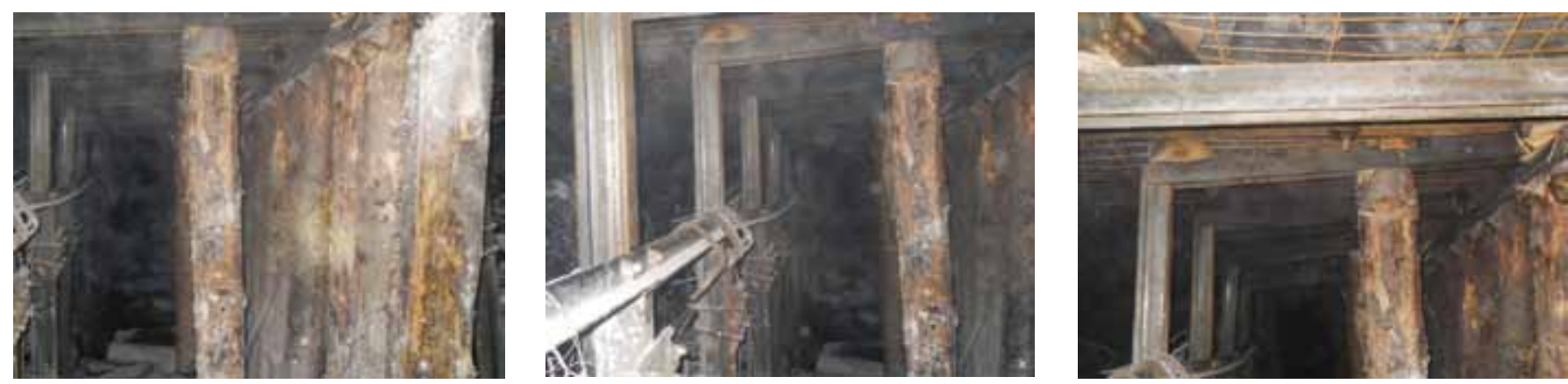

Puс. 4. Состояние сохраняемой части вентилячионного штрека № 26-25 бис

На шахте «Листвяжная» нами был применен комплексный метод управления геомеханическим состоянием горного массива, включающий бурение разгрузочных скважин и метод направленного гидроразрыва, при отработке выемочного столба лавы № 823 пласта «Сычевский |». Это позволило снизить конвергенцию кровли и почвы вентиляционного штрека № 823 в зоне опорного давления (см. таблицу).

Проектная высота выработки составляет 3,5 м, шаг между пикетами - 10 м. После начала ведения комплекса работ по разгрузке пласта и разупрочнению кровли значительно снизилась интенсивность пучения почвы и смещений кровли при подходе очистного забоя. Так, 03.03.2021, проектное сечение выработки сохранялось на расстоянии не менее 130 м до очистного забоя, а 09.03.2021 - на расстоянии не менее $80 \mathrm{~m}$.

Для разгрузки краевой части пласта и межлавного целика в вентиляционном штреке были использованы скважины НГР, пробуренные с наклоном на целик угля и выемочный столб, с шагом заложения скважин, равным 15 м, и разгрузочные скважины, пробуренные в наиболее мощной пачке угля (рис. 5).

С целью снижения последующих шагов обрушения пород основной кровли дополнительно производилось разупрочнение кровли скважинами НГР глубокого заложения. Вертикальные скважины НГР длиной 20 м обеспечивают расслоение пород кровли и необходимое подбучивание вышележащей толщи, а наклонные скважины дли- ной 22,6 м - отсечение кровли и ликвидацию ее зависания в выработанном пространстве (рис. 6).

По результатам сейсмического просвечивания [23] до и после НГР (рис. 7) зафиксированы изменения состояния активной кровли, выраженные в снижении скоростного фона в исследуемой области и сокращении площади зон А, Б, В. В целом, изменения размеров и взаимного расположения указанных зон в результате гидровоздействия свидетельствуют о разгрузке кровли и снижении вероятности формирования участка труднообрушающейся основной кровли в исследованном интервале.

\section{выводы}

Таким образом, совокупное применение метода гидродинамической стратификации, направленного гидроразрыва и способов разгрузки угольного пласта позволяет решать различные технологические задачи при разработке угольных пластов с тяжелой кровлей при ее полном обрушении. При этом важную роль играют ориентация трещины НГР относительно напластования пород и ее распространение в заданном направлении на расчетную длину, что в свою очередь требует применения инструментальных и геофизических методов эффективного контроля над процессом гидрообработки.

Потенциал применяемых методов направленного и управляемого процесса трещинообразования в породах труднообрушаемой кровли далеко не раскрыт. Недостаточно широкое его применение ограничивает опыт наблю-

\section{Измерения конвергенции кровли и почвы вентиляционного штрека № 823 в зоне опорного давления}

\begin{tabular}{|c|c|c|c|c|c|c|}
\hline \multirow{2}{*}{$\begin{array}{l}\text { Номер замерной } \\
\text { станции }\end{array}$} & \multirow{2}{*}{ Пикет } & \multicolumn{3}{|c|}{ Высота выработки, м } & \multirow{2}{*}{$\begin{array}{c}\text { Ширина } \\
\text { выработки, м }\end{array}$} & \multirow{2}{*}{$\begin{array}{c}\text { Площадь сечения } \\
\text { выработки в свету, м² }\end{array}$} \\
\hline & & 03.03 .2021 & 06.03 .2021 & 09.03 .2021 & & \\
\hline 1 & 25 & 3,5 & 3,5 & 3,5 & 5,8 & 20,4 \\
\hline 2 & 26 & 3,0 & 3,0 & 3,5 & 5,7 & 17,3 \\
\hline 3 & 27 & 2,8 & 2,8 & 3,0 & 5,4 & 15,5 \\
\hline 4 & 28 & 2,8 & 2,8 & 2,2 & 5,7 & 16,2 \\
\hline 5 & 29 & 2,8 & 2,8 & 1,9 & 5,5 & 15,7 \\
\hline 6 & 30 & 2,5 & 2,5 & 1,7 & 5,3 & 13,4 \\
\hline 7 & 31 & 2,3 & 1,7 & 1,3 & 5,9 & 14 \\
\hline 8 & 32 & 1,7 & 1,5 & 1,1 & 4,9 & 8,2 \\
\hline 9 & 33 & 1,8 & 1,4 & - & 4,6 & 8,4 \\
\hline 10 & 34 & 1,4 & 1,1 & - & 4,9 & 7,3 \\
\hline 11 & 35 & 1,2 & $1-0,9$ & - & 4,5 & 5,8 \\
\hline 12 & 36 & 1,5 & - & - & 6 & 9,3 \\
\hline 13 & 37 & 1,4 & - & - & 4 & 5,4 \\
\hline 14 & 38 & 1 & - & - & 5,5 & 5,7 \\
\hline
\end{tabular}




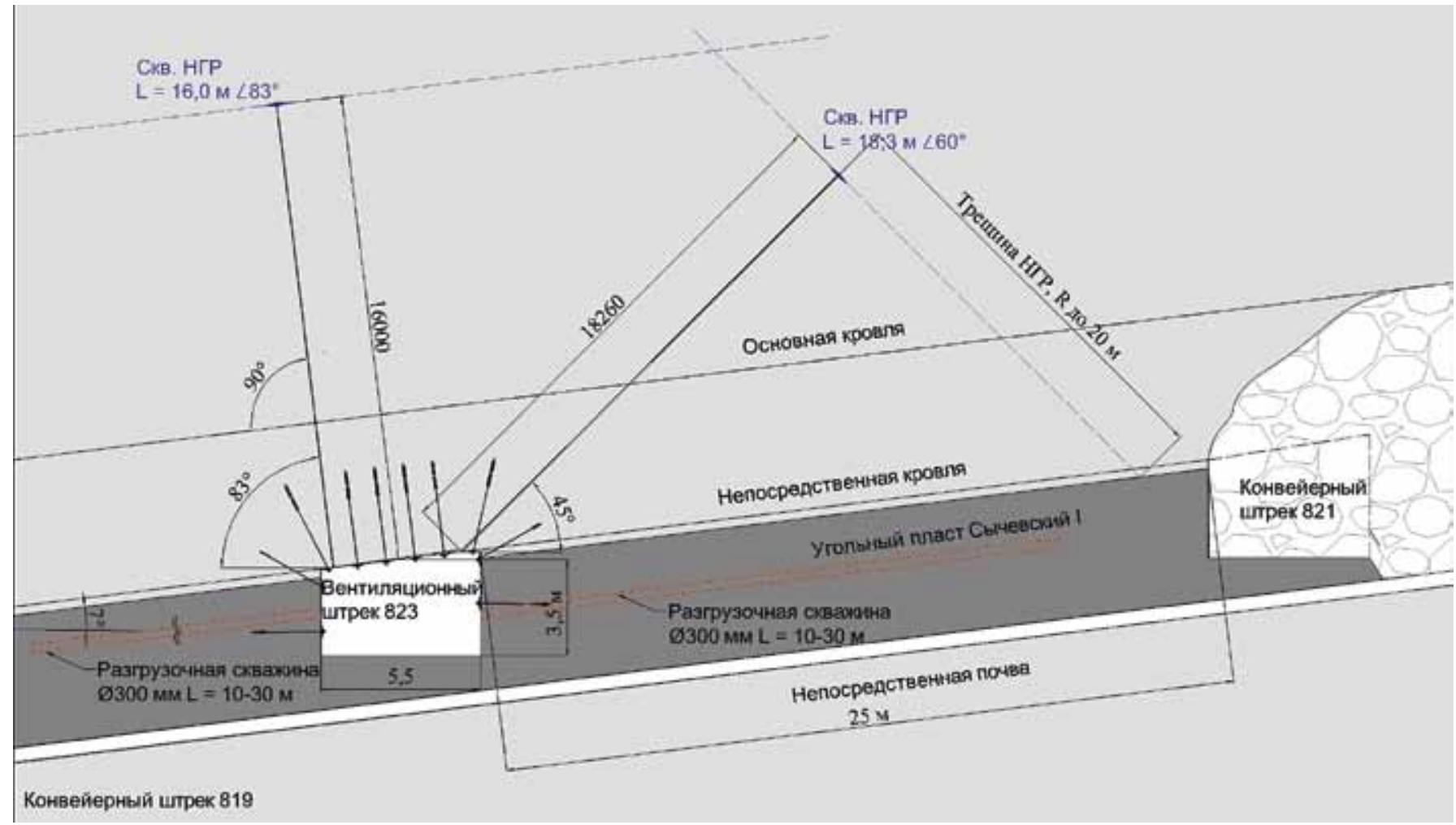

Pис. 5. Схема заложения скважин НГР и разгрузочных скважин в вентиляционном штреке № 823

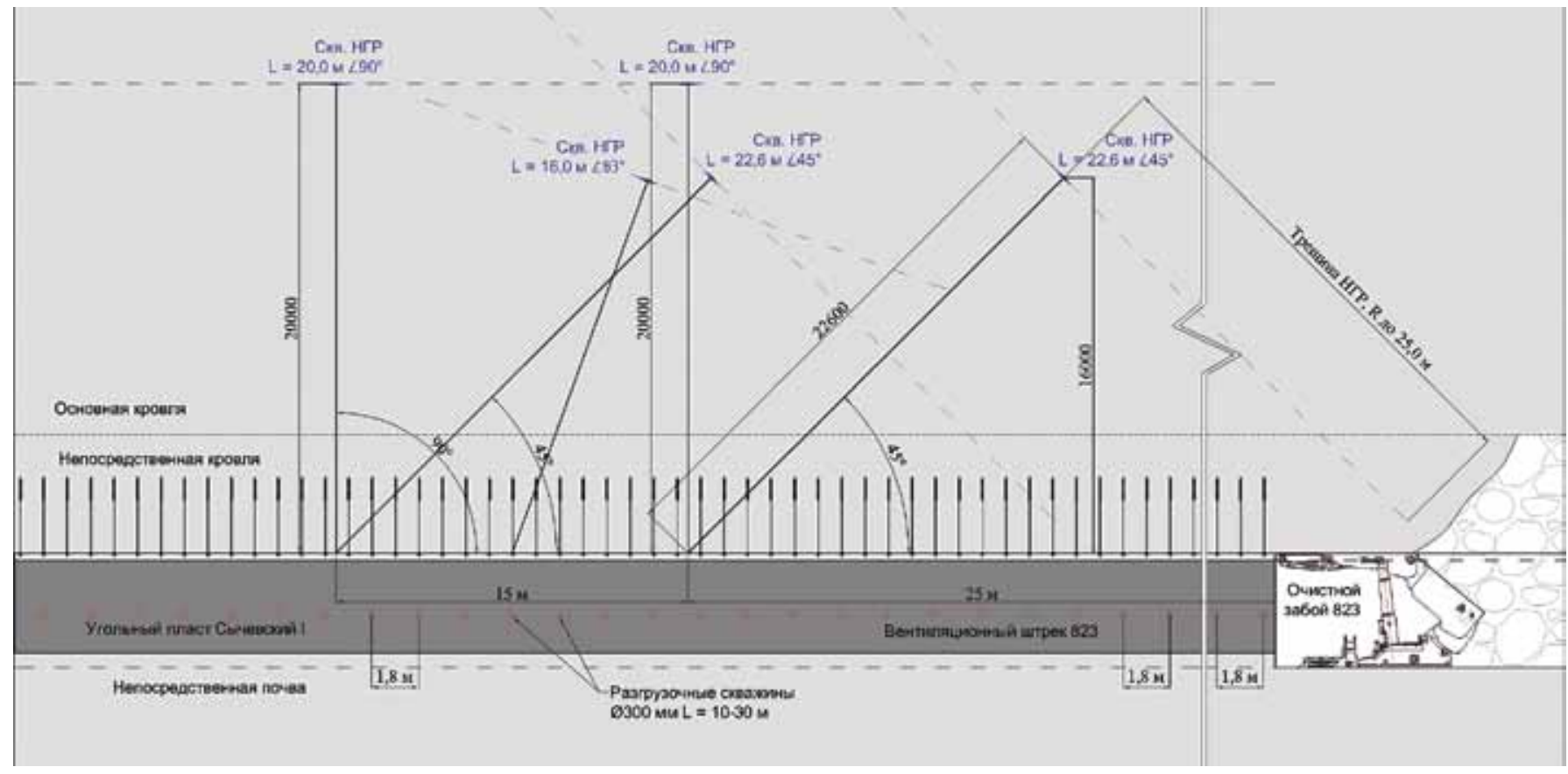

Pис. 6. Схема расположения скважин НГР глубокого заложения и разгрузочных скважин в угле

дений, развитие техники и разработку новых технологических схем. Кроме того, освоение технологии создания протяженных направленных трещин в крепком монолитном массиве позволит не только снижать вертикальную составляющую горного давления за счет уменьшения нависающих консолей и снижения шага обрушения пород в процессе очистной выемки, но и изменять направление вектора этих сил, отклоняя его от охраняемых объектов. Так, например, две наклонные плоскости трения, сформированные такими трещинами по обе стороны от горной выработки, перераспределят часть вертикальной составляющей горного давления в субгоризональное. Это может использоваться в качестве меры от повышенного давления на крепь и бока выработки, от пучения почвы, для снижения стоимости и продления срока эксплуатации выработки. Возможно использование направленного трещинообразования в качестве меры предупреждения динамических явлений, создания газовых коллекто- 
$a$

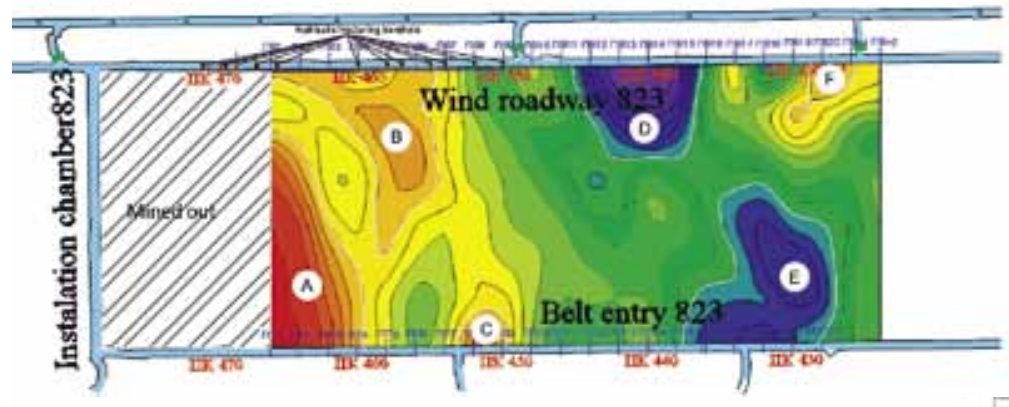

6

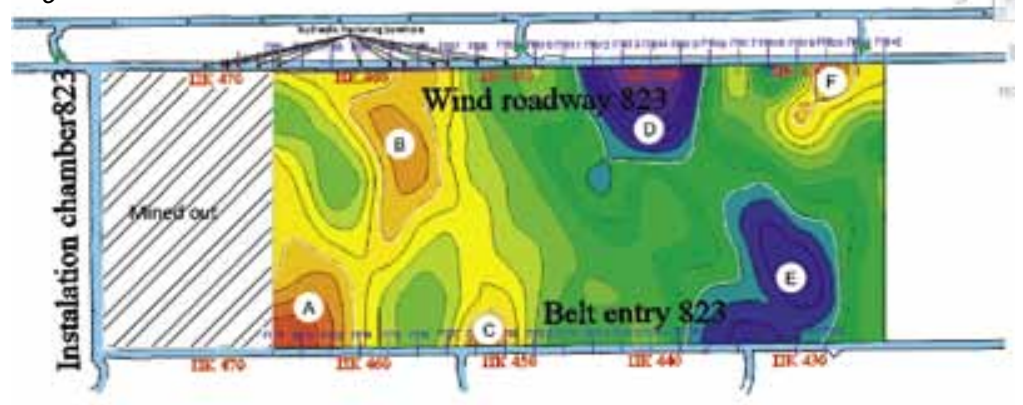

Рис. 7. Результаты сейсмического просвечивания активной кровли: а -до гидравлического воздействия;

б - после гидравлического воздействия

ров и повышения площади газоотдачи при дегазации. Для раскрытия всего потенциала метода НГР необходимы его популяризация, наработка еще более обширного производственного опыта в различных условиях.

\section{Список литературы}

1. Охрана подготовительных выработок целиками на угольных шахтах / В.Б. Артемьев, Г.И. Коршунов, А.К. Логинов и др. // СПб.: Наука, 2009. 231 с.

2. Труднообрушаемые кровли: проблемы и решения для механизированных забоев современного технического уровня угольных шахт / В.И. Клишин, В.В. Рашевский, В.Б. Артемьев и др. М.: Издательство «Горное дело» ООО «Киммерийский центр», 2016. 480 с.

3. Проблемы безопасности и новые технологии подземной разработки угольных месторождений / В.И. Клишин, Л.В. Зворыгин, А.В. Лебедев и др. Новосибирск: Издательский дом «Новосибирский писатель», 2011. 524 с.

4. Оганесян С.А. Авария в Филиале «Шахта Тайжина» ОАО ОУК «Южкузбассуголь» - хронология, причины, выводы // Уголь. 2004. № 6. С. 25-28.

5. Цивка Ю.В., Петров А.Н. Гидродинамические явления на руднике Баренцбург архипелага Шпицберген // Уголь. 2005. № 7. C. 49-50.

6. Li T., Cai M.F., Cai M. A review of mining-induced seismicity in China // International Journal of Rock Mechanics and Mining Sciences. 2007. Vol. 44. P. 1149-1171.

7. Prevention and forecasting of rock burst hazards in coal mines / L.M. Dou, C.P. Lu, Z.L. Mu et al. // Mining Science and Technology (China). 2009. Vol. 19. P. 585-591.

8. Application of rock directional hydraulic fracture /T.T. Du, L.M. Dou, J.W. Yang et al. // Coal Mining Technology. 2010. Vol. 15. P. 4-7.

9. Deep-hole directional fracturing of thick hard roof for rockburst prevention / H. He, L. Dou, J. Fan et al. //Tunnelling and Underground Space Technology. 2012. Vol. 32. P. 34-43.
10. Directional hydraulic fracturing to control hard-roof rockburst in coal mines / Fan Jun, Dou Linming, He Hu et al. China University of Mining \& Technology, 2012.

11. Monitoring and measuring hydraulic fracturing growth during preconditioning of a roof rock over a coal longwall panel / R. Jeffrey, Z. Chen, S. Pegg et al. / ISRM International Conference for Effective and Sustainable Hydraulic Fracturing. International Society for Rock Mechanics and Rock Engineering, 2013.

12. Jackson M.J., Tweeton D.R. MIGRATOM - Geophysical Tomography Using Wavefront Migration and Fuzzy Constraints / Report of Investigations 9497, Bureau of Mines. URL: http://pubs.usgs.gov/ of/2000/ofr-00-0457/ (дата обращения: 15.10. 2021).

13. Three dimensional forms of closely-spaced hydraulic fractures / J. Kear, J. White, A.P. Bunger et al. / The International Conference for Effective and Sustainable Hydraulic Fracturing. 20-22 May, 2013. Brisbane, Australia, In Tech: Rijeka, Croatia.

14. Van As.A., Jeffrey R.G. Caving induced by hydraulic fracturing at Northparkes Mines / The Fourth North American Rock Mechanics Symposium. 31 July - 3 August, 2000. Seattle, WA, USA, Rotterdam.

15. Experimental investigation of the interaction among closely spaced hydraulic fractures / A. Bunger, R. Jeffrey, J. Kear et al. / In 45th US Rock Mechanics / Geomechanics Symposium. 26-29 June, 2011. San Francisco, CA, USA ARMA.

16. Jeffrey R.G, Mills K.W. Hydraulic fracturing applied to inducing longwall coal mine goaf falls / The Fourth North American Rock Mechanics Symposium. 31 July - 3 August, 2000. Seattle, WA, USA, Rotterdam.

17. Measurement and Analysis of Full-Scale Hydraulic Fracture Initiation and Reorientation / R.G. Jeffrey, Z.R. Chen, X. Zhang et al. // Rock Mechanics and Rock Engineering. 2015. Vol. 48. P. 2497-2512.

18. Инструкция по выбору способа и параметров разупрочнения кровли на выемочных участках. Л.: ВНИМИ, 1991. 102 c.

19. Чернов О.И., Кю Н.Г. О флюидоразрыве породных массивов // ФТПРПИ. 1988. № 6.

20. Клишин В.И. Адаптация механизированных крепей к условиям динамического нагружения. Новосибирск: Наука, 2002. 200 с.

21. Джевецки Ян. Новые методы предотвращения опасности горных ударов // Глюкауф. 2002. № 2. С. 18-21.

22. Dubinski J.A. Geophysical assessment of the hydraulic injection process in coal seams under rockburst hazard / Geomechanics 93. Proc. Conference, Ostrava, 1994. P. 55-58.

23. Тайлаков О.В., Соколов С.В., Салтымаков Е.А. Определение свойств кровли в пределах выемочного столба на основе применения автономных сейсмических регистраторов в шахтных геофизических измерениях // Наукоемкие технологии разработки и использования минеральных ресурсов: сб. науч. статей Междунар. научн.-практ. конф. Новокузнецк, 2018. № 4. С. 437-441. 
UDC 622.831.24:622.833.5:539.219.2 @ V.I. Klishin, G.Yu. Opruk, A.S. Teleguz, A.V. Nikolaev, S.I. Machrakov, I.A. Pechenev, 2021

ISSN 0041-5790 (Print) • ISSN 2412-8333 (Online) • Ugol' - Russian Coal Journal, 2021, № 11, pp. 6-12

DOI: http://dx.doi.org/10.18796/0041-5790-2021-11-6-12

\section{Title}

IMPLEMENTATION OF DIRECTIONAL HYDRAULIC FRACTURING (DHF)

IN TACKING GEOTECHNOLOGICAL CHALLENGES OF MANAGING EXCESSIVE ROCK PRESSURE

\section{Authors}

Klishin V.I. ${ }^{1}$, Opruk G.Yu. ${ }^{1}$, Teleguz A.S. ${ }^{1}$, Nikolaev A.V. ${ }^{2}$, Machrakov S.I. ${ }^{3}$, Pechenev I.A. ${ }^{4}$

${ }^{1}$ Institute of Coal of Federal Research Center of Coal and Coal-Chemistry of SB RAS, Kemerovo, 650065, Russian Federation

2 "Esaulskaya" Mine" LLC, Novokuznetsk, 654006, Russian Federation

3 "Listvyazhnaya" Mine" LLC, village Gramoteino, Kemerovo region, 652614, Russian Federation

4 "KaryeroUpravlenie N 42" LLC, Prokopyevsk, 653047, Russian Federation

\section{Authors Information}

Klishin V.I., Doctor of Engineering Sciences, Professor,

RAS Corresponding Member, Director, e-mail: klishinvi@icc.kemsc.ru

Opruk G.Yu., Ph.D. (Engineering), Head of Efficient Coal Deposits

Development Laboratory, e-mail: opruk@yandex.ru

Teleguz A.S., Junior Researcher, e-mail: alexanderteleguz@rambler.ru

Nikolaev A.V., Deputy Chief Technology Engineer,

e-mail: Aleksey.Nikolaev4@evraz.com

Machrakov S.I., General Director, e-mail: office2@list.hcsds.ru

Pechenev I.A., Director, e-mail: ooo@ku42.ru

\section{Abstract}

The paper presents the use of directional hydraulic fracturing (DHF) method to manage poorly caving roofs in coal mines and the means of its implementation. The experience of implementing this method in Kuzbass coa mines is analysed for various technological tasks, e.g. maintenance of reused development drifts; reduction of primary and subsequent steps in roof cav ing, floor heave control ahead of the working face, gas release into the stope. The results of monitoring and mine experiments on roof control using the method of seismic sounding of the extraction pillar with transmitted waves are presented.

\section{Keywords}

Rock pressure management, Mine support, Directional hydraulic fracturing Poorly caving roof.

\section{References}

1. Artemiev V.B., Korshunov G.I., Loginov A.K. et al. Protection of development drifts with pillars in coal mines. St. Petersburg, Nauka Publ., 2009, 231 p. (In Russ.).

2. Klishin V.I., Rashevsky V.V., Artemiev V.B. et al. Hard-to-break roof formations: challenges and solutions for state-of-the-art mechanized longwalls in coal mines. Moscow, Gornoe Delo Publ., Cimmerian Centre LLC, 2016, 480 p. (In Russ.).

3. Klishin V.I., Zvorygin L.V., Lebedev A.V. et al. Safety issues and new technologies in underground mining of coal deposits. Novosibirsk: Novosibirskiy Pisatel' Publ., 2011, 524 p. (In Russ.).

4. Oganesyan S.A. Accident in "Taizhina Mine" Branch of "Yuzhkuzbassugol" JSC: chronology, causes, conclusions. Ugol', 2004, (6), pp. 25-28. (In Russ.).

5. Tsivka Yu.V. \& Petrov A.N. Hydrodynamic phenomena at the Barentsburg mine of the Spitzbergen archipelago. Ugol', 2005, (7), pp. 49-50. (In Russ.).

6. Li T., Cai M.F. \& Cai M. A review of mining-induced seismicity in China. International Journal of Rock Mechanics and Mining Sciences, 2007, Vol. 44, pp. 1149-1171.

7. Dou L.M., Lu C.P., Mu Z.L. et al. Prevention and forecasting of rock burst hazards in coal mines. Mining Science and Technology (China), 2009, Vol. 19, pp. 585-591.

8. Du T.T., Dou L.M., Yang J.W. et al. Application of rock directional hydraulic fracture. Coal Mining Technology, 2010, Vol. 15, pp. 4-7.

9. He H., Dou L., Fan J. et al. Deep-hole directional fracturing of thick hard roof for rockburst prevention. Tunnelling and Underground Space Technology, 2012, Vol. 32, pp. 34-43.

10. Fan Jun, Dou Linming, He Hu et al. Directional hydraulic fracturing to control hard-roof rockburst in coal mines. China University of Mining \& Technology, 2012.
11. Jeffrey R., Chen Z., Pegg S. et al. Monitoring and measuring hydraulic fracturing growth during preconditioning of a roof rock over a coal longwall panel /ISRM International Conference for Effective and Sustainable Hydraulic Fracturing. International Society for Rock Mechanics and Rock Engineering, 2013. 12. Jackson M.J. \& Tweeton D.R. MIGRATOM - Geophysical Tomography Using Wavefront Migration and Fuzzy Constraints / Report of Investigations 9497 Bureau of Mines. Available at: http://pubs.usgs.gov/of/2000/ofr-00-0457/ (accessed 15.10.2021).

13. Kear J., White J., Bunger A.P. et al. Three dimensional forms of closelyspaced hydraulic fractures / The International Conference for Effective and Sustainable Hydraulic Fractur-ing., 20-22 May, 2013, Brisbane, Australia, In Tech: Rijeka, Croatia.

14. Van As.A. \& Jeffrey R.G. Caving induced by hydraulic fracturing at Northparkes Mines / The Fourth North American Rock Mechanics Symposium, 31 July - 3 August, 2000, Seattle, WA, USA, Rotterdam.

15. Bunger A., Jeffrey R., Kear J. et al. Experimental investigation of the interaction among closely spaced hydraulic fractures / In $45^{\text {th }}$ US Rock Mechanics. Geomechanics Symposium, 26-29 June, 2011, San Francisco, CA, USA ARMA 16. Jeffrey R.G. \& Mills K.W. Hydraulic fracturing applied to inducing longwall coal mine goaf falls / The Fourth North American Rock Mechanics Symposium, 31 July - 3 August, 2000, Seattle, WA, USA, Rotterdam.

17. Jeffrey R.G., Chen Z.R., Zhang X. et al. Measurement and Analysis of FullScale Hydraulic Fracture Initiation and Reorientation. Rock Mechanics and Rock Engineering, 2015, Vol. 48, pp. 2497-2512.

18. Guidelines for selecting the method and parameters for roof weakening in extraction zones. Leningrad, VNIMI Publ., 1991, 102 p. (In Russ.).

19. Chernov O.I. \& Kyu N.G. On fluid fracture of rock massifs. Fiziko-tehničeskie problemy razrabotki poleznyh iskopaemyh, 1988, (6). (In Russ.).

20. Klishin V.I. Adaptation of powered support to dynamic stress conditions. Novosibirsk, Nauka Publ., 2002, 200 p. (In Russ.).

21. Drzewiecki J. Neue Verfahren zur Bekämpfung der Gebirgsschlaggefahr Gluckauf, 2002, (2), pp. 18-21. (In Russ.).

22. Dubinski J.A. Geophysical assessment of the hydraulic injection process in coal seams under rockburst hazard / Geomechanics 93. Proc. Conference, Ostrava, 1994, pp. 55-58.

23. Tailakov O.V., Sokolov S.V. \& Saltymakov E.A. Determination of roof properties within the extraction pillar using autonomous seismic loggers in mine geophysical measurements. Science-intensive technologies of development and use of mineral resources: Proceedings of the International Scientific and Practical Conference. Novokuznetsk, 2018, (4), pp. 437-441. (In Russ.).

\section{Acknowledgements}

The research was supported by the Russian Science Foundation Grant (Project No.17-17-01143)

\section{For citation}

Klishin V.I., Opruk G.Yu., Teleguz A.S., Nikolaev A.V., Machrakov S.I. \& Pechenev I.A. Implementation of Directional Hydraulic Fracturing (DHF) in tacking geotechnological challenges of managing excessive rock pressure. Ugol,' 2021, (11), pp. 6-12. (In Russ.). DOI: 10.18796/0041-5790-2021-11-6-12.

\section{Paper info}

Received September 21, 2021

Reviewed October 4, 2021

Accepted October 15, 2021 